\title{
Actividade Científica do GEsOS em 2021
}

Scientific Activity of GESOS in 2021

Isabel Cristina Fernandes

\section{(2) OpenEdition}

Journals

Edição electrónica

URL: https://journals.openedition.org/medievalista/5224

ISSN: 1646-740X

\section{Editora}

Instituto de Estudos Medievais - FCSH-UNL

\section{Refêrencia eletrónica}

Isabel Cristina Fernandes, «Actividade Científica do GEsOS em $2021 »$, Medievalista [Online], 31 | 2022, posto online no dia 01 janeiro 2022, consultado o 02 fevereiro 2022. URL: http:// journals.openedition.org/medievalista/5224

Este documento foi criado de forma automática no dia 2 fevereiro 2022.

\section{c) (i) (8)}

Mediavalista está licenciado com uma Licença Creative Commons - Atribuição-NãoComercial 4.0 Internacional. 


\section{Actividade Científica do GEsOS em 2021}

Scientific Activity of GESOS in 2021

Isabel Cristina Fernandes

\section{NOTA DO EDITOR}

Universidade Nova de Lisboa, Faculdade de Ciências Sociais e Humanas, Instituto de Estudos Medievais, 1099-032 Lisboa, Portugal. Gabinete de Estudos sobre a Ordem de Santiago - Município de Palmela, 2954-001 Palmela, Portugal . Universidade de Évora, Centro Interdisciplinar de História, Culturas e Sociedades, 7000-849 Évora, Portugal. isacrisff.ed@gmail.com. https://orcid.org/0000-0003-0725-7768

Data recepção do artigo / Received for publication: 8 de Dezembro de 2021

1 O GEsOS - Gabinete de Estudos sobre a Ordem de Santiago, do Município de Palmela, foi criado em 1997 e passou a funcionar em instalações próprias, no castelo de Palmela, desde 2001. Nas suas finalidades inclui a promoção da investigação historiográfica na área dessas Ordens, a divulgação do património histórico, documental, arqueológico e edificado das Ordens Militares e a publicação de estudos nesta área. No âmbito temático da sua ação integra ainda a arquitectura militar, que não apenas a relacionada com as Ordens Militares.

Depois do difícil ano de 2020, em contexto pandémico, o GEsOS apostou, em 2021, na retoma da atividade com privilégio do reencontro presencial, que sempre considerou determinante para um bom clima de comunicação. Assim, calendarizou e concretizou uma série de iniciativas que, na sua maioria, se concentraram no outono de 2021.

3 A primeira delas, a que rompeu o ciclo de enclausuramento e de opções on-line, foi o $17 .{ }^{\circ}$ Curso sobre Ordens Militares, intitulado Casas das Ordens Militares, com coordenação científica de Luís Filipe Oliveira, que se desenvolveu em 22 e 23 de maio, em parceria com o Instituto de Estudos Medievais da Universidade Nova de Lisboa. 0 tema deste 
curso centrou-se na análise das casas das comendas das Ordens, num propósito iniciado num outro curso, em 2014, que incidiu sobre as comendas urbanas e cujos textos foram publicados (Edições Colibri, 2016). Neste 17. Curso estudaram-se aspectos da organização e gestão das casas e comendas, as redes que estabeleciam, os recrutamentos que faziam em meio urbano, os cultos que nelas se promoviam, os negócios e as explorações que dinamizavam e que proporcionavam às Ordens os necessários proventos.

4 Luís Oliveira abriu o curso com uma reflexão sobre a relevância de conhecer melhor essas casas, sobretudo ao nível da sua organização e gestão, do relacionamento com as elites locais, do seu envolvimento no quotidiano económico e social urbano. Paula Pinto Costa reflectiu sobre 0 património edificado de Leça do Balio, Saúl Gomes falou das Comendas das Ordens Militares em Coimbra, Mário Viana abordou $O$ património urbano e rural das Ordens Militares em Santarém nos séculos XII-XIV e coube a Mário Farelo tratar das Ordens Militares na Lisboa medieval. As casas e comendas a sul do Tejo foram analisadas por Rui Mesquita Mendes, que dissertou sobre A Ordem de Santiago em Almada, por José Manuel Vargas, sobre A importância local das comendas de Alhos Vedros, Aldeia Galega e Alcochete e por Joaquim Serra, sobre o Património urbano das Ordens Militares na Évora Tardo Medieval.

5 As sessões teóricas terminaram com o lançamento da obra das Edições Colibri "As Origens da Ordem de Santiago em Portugal", da autoria do historiador Mário Cunha.

o segundo dia foi dedicado a uma visita de estudo ao património arquitectónico e artístico de Alcochete e de Alhos Vedros (Moita) relacionado com a Ordem de Santiago.

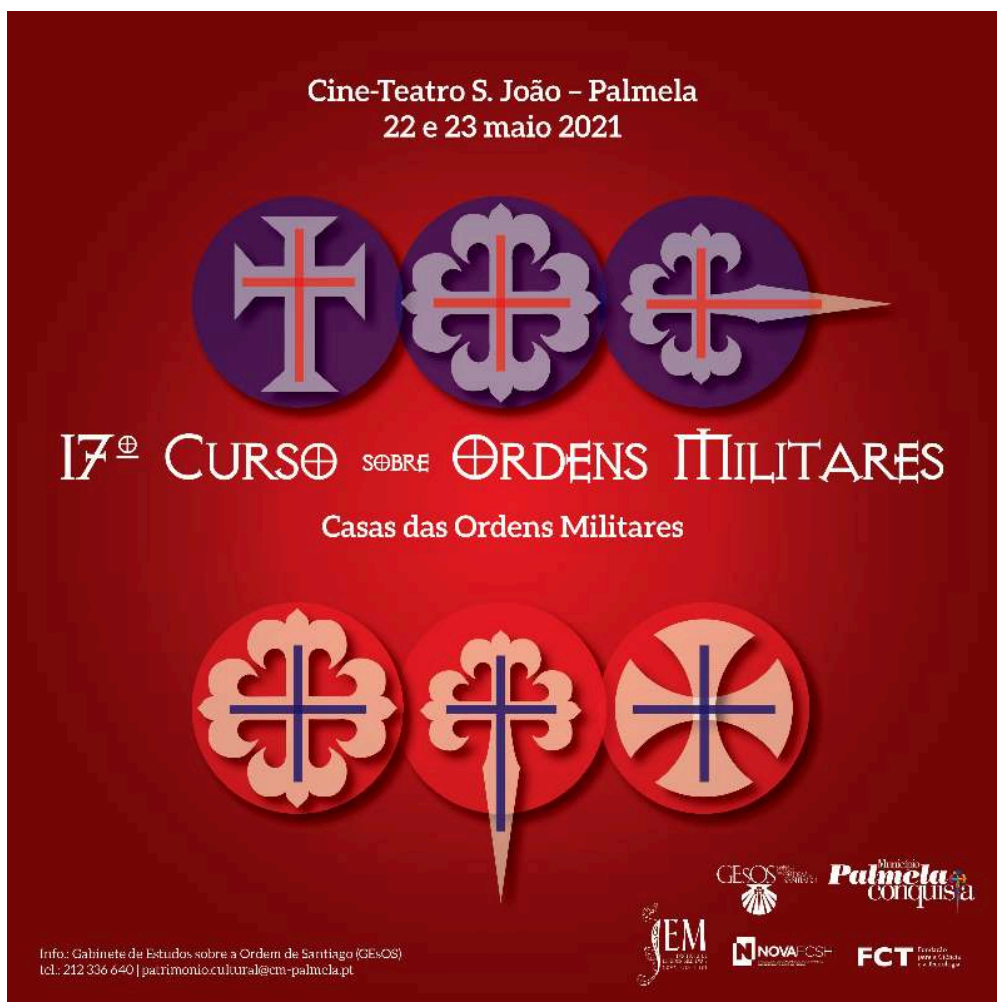

Fig. 1 - Cartaz do 17. ${ }^{\circ}$ Curso sobre Ordens Militares.

7 Em 10 e 11 de setembro de 2021 foi a vez de, em parceria com a AIHM - Associação Ibérica de História Militar (Séculos IV-XVI), organizar e realizar um colóquio sobre o tema Recrutamento e Organização Militares na Península Ibérica (séculos IV-XVI). 
8 A Associação Ibérica de História Militar foi criada em 2015 e tem sido dirigida pelos professores João Gouveia Monteiro (Universidade de Coimbra) e Francisco García Fitz (Universidade de Extremadura), apresentando como principais objetivos: promover estudos de história militar entre os séculos IV a XVI, em especial da Península Ibérica; organizar reuniões científicas sobre esta temática; estimular projetos de investigação e publicações conjuntas e colaborar com outras associações congéneres, nacionais ou estrangeiras. $\mathrm{O}$ colóquio reuniu um grupo significativo de comunicantes, na sua maioria jovens, que partilharam com os assistentes as novidades das suas pesquisas e proporcionaram interessantes debates. Contou com uma abordagem à organização e administração militares na "Spania Bizantina" (Gustavo Gonçalves), estudos de caso para Valencia, sécs. XIII-XV (Pablo Sanahuja Ferrer) e para a região de Ribacoa, séculos XII-XIII (Carlos Afonso). Foram tratados aspectos da mobilização militar nos concelhos alentejanos no reinado de D. João I (João Rafael Nisa) e, mais especificamente, a mobilização portuguesa e castelhano-leonesa para a batalha de Aljubarrota (José Luís Costa Hernandéz). A cadeia de comando nas frotas do Portugal medieval foi analisada por Elise Cardoso. Os finais da Idade Média foram contemplados com quatro intervenções: $O$ corpo dos espingardeiros em Portugal, no século XV, por Pedro Sebastião; De armas vestidos: as guarnições portuguesas no Magrebe nos finais da Idade Média, por António Martins Costa; Mouriscos e Mouros de Pazes na organização militar portuguesa no Norte de África, c. 1459-1518, por Paulo Dias; Arcabuceros en la conquista de México, 1519-1521, por Dario Testi.

9 A conferência de encerramento ficou a cargo do presidente da direção da AIHM, João Gouveia Monteiro. Sob o título O Recrutamento para a Guerra no Portugal medieval. Certezas e Interrogações, expôs o ponto de situação da investigação nesta temática e delineou caminhos a percorrer, especificando as áreas para as quais, na sua perspectiva, será importante direccionar a pesquisa.

10 O evento integrou ainda a apresentação do estudo vencedor da III edição do Prémio Jovens Investigadores (prémio instituído pela AIHM e patrocinado pelo Banco Santander) - "Estrategia y Táctica Militar en la Castilla del siglo XV, 1407-1492", da autoria de Ekaitz Etxeberría Gallastegi, doutorado em História pela Universidad del País Vasco. Compreendeu ainda a apresentação de três livros: duas obras colectivas, publicadas pela editora La Ergástula: "Fechos de Armas. 15 hitos bélicos del Medievo Ibérico (siglos XI-XVI)" e "De Fusta e de Fierro. Armamento Medieval Cristiano en la Península Ibérica (SS. XI-XVI)", o primeiro coordenado por Martín Alvira Cabrer e o segundo por este mesmo investigador e por Miguel Gomes Martins; a obra Recrutamento no exército português. Do Condado Portucalense ao Século XXI, coordenada por Luís Barroso e Carlos Filipe Afonso, uma edição Fronteira do Caos e Comando do Pessoal do Exército.

11 O colóquio terminou, na tarde do segundo dia, com uma visita de estudo ao Castelo de S. Jorge, orientada pela directora do monumento, Maria Antónia Amaral. 


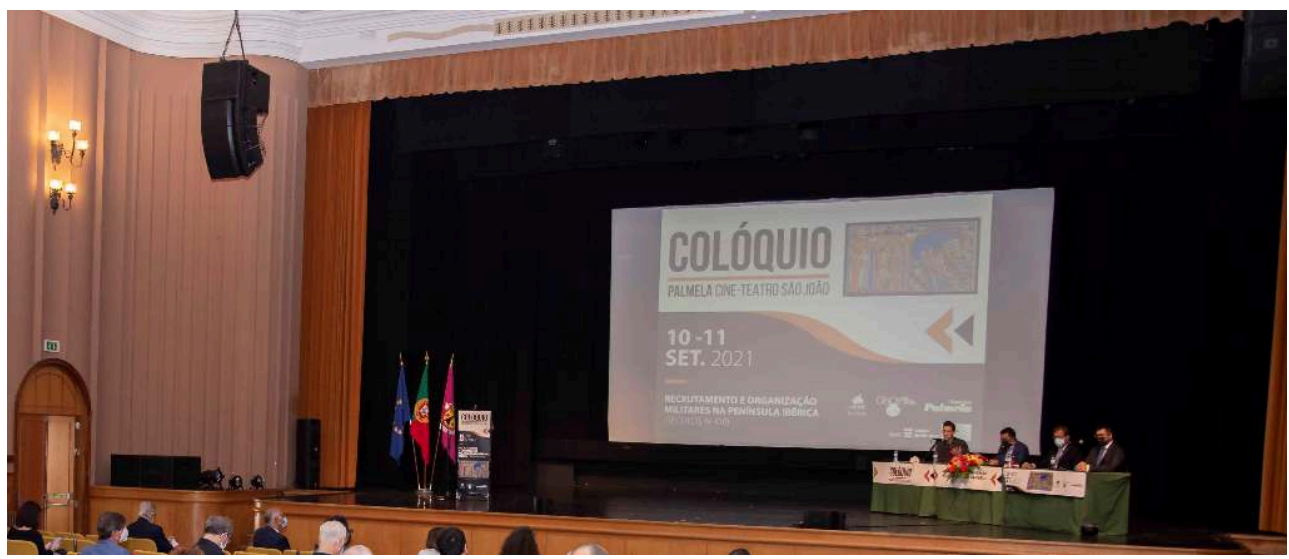

Fig. 2 - Sessão de trabalhos do colóquio Recrutamento e Organização Militares na Península Ibérica (séculos IV-XVI). Foto Paulo Alexandre-CMP.

12 Um mês depois, a 9 e 10 de outubro, no âmbito do Dia Nacional dos Castelos, o GEsOS levou a efeito o curso Castelos e Muralhas Urbanas no Portugal Medieval, dirigido por Luísa Trindade, da Faculdade de Letras da Universidade de Coimbra.

13 A atratividade do tema "castelos medievais" levou a Palmela cerca de oito dezenas de participantes. No primeiro dia de sessões aprenderam mais sobre a defesa das cidades nesse período, a evolução das suas muralhas e castelos, as suas múltiplas funcionalidades, a relação intra e extra-muros, os casos de Porto, Lisboa e Évora e ainda o restauro destas estruturas no séc. XX e a forma como as conhecemos e usamos hoje. $\mathrm{O}$ segundo dia compreendeu uma visita de estudo, também orientada por Luísa Trindade, aos castelos de Pombal, da Lousã e de Montemor-o-Velho.

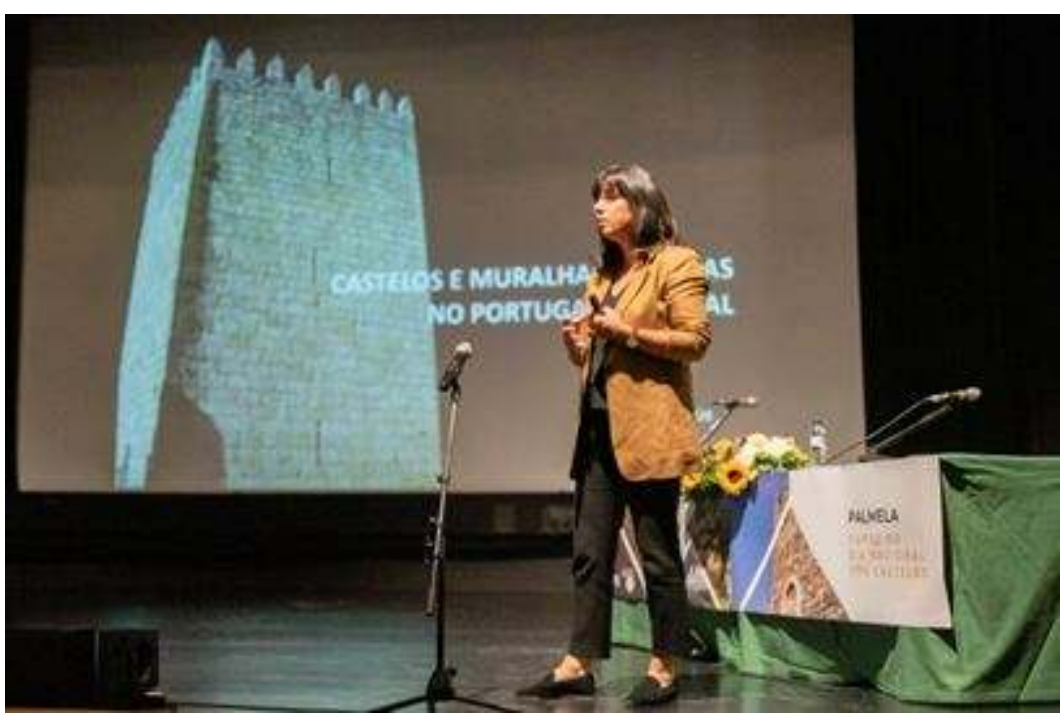

Fig. 3 - Sessão do curso Castelos e Muralhas Urbanas no Portugal Medieval. Foto Paulo Alexandre CMP.

14 A 30 de outubro, em colaboração com a Mostra Espanha 2021 (Ministério da Cultura de Espanha), o GEsOS co-organizou em Palmela três eventos centrados no tema do Caminho de Santiago. o primeiro foi o Colóquio Espanha, Portugal e o Caminho de Santiago. Caminhos do Caminho, coordenado por Feliciano Novoa Portela e pela subscritora desta notícia.

15 O Mito de Santiago, por Feliciano Novoa e O Norte Peninsular ao Tempo da Descoberta do Túmulo de Santiago, por Paulo Almeida Fernandes, proporcionaram o enquadramento 
histórico e lendário das origens do culto a São Tiago e da peregrinação compostelana. José António Falcão, com uma comunicação intitulada Peregrinatio ad limina: Dinâmicas, Motivações, Tipologias, dirigiu a atenção para a dimensão do sagrado, dos rituais e da imagem nas peregrinações de diversas religiões, para deter-se depois na análise das práticas cristãs neste domínio. A aproximação pela via da história da arte foi protagonizada por Carla Varela Fernandes, que através da intervenção Com Bordão ou com Espada. Representar Santiago em Portugal na Idade Média forneceu a sua leitura da imaginária relacionada com o santo.

o Caminho para a Música, por Manuel Pedro Ferreira, conduziu os assistentes numa viagem pela música que se tocava e escutava nos contextos medievos do Caminho e Viriato Soromenho Marques, em Um Caminho para a Natureza, dissertou sobre e relação entre o peregrino e a natureza, a remeter para uma mensagem ecológica.

o formato do colóquio foi definido com dois momentos de debate: um primeiro, de cariz filósófico, entre um pensador de pendor racionalista, João Zilhão e uma mística, amante do sufismo, Mardía Herrero; um segundo, pensado para a troca de opiniões no âmbito da trilogia Turismo, Religião e Cultura, em ano Jacobeu, e que teve como intervenientes Teresa Ferreira, do Turismo de Portugal e Cecília Pereira, comissária do Xacobeo 2021/22. O colóquio foi seguido por dois eventos no Castelo de Palmela - Igreja de Santiago: a inauguração da exposição de pintura de Alicia Aradilla "O Caminho Ilustrado", patrocinada pela AFundación (ABanca) e o concerto de guitarra "Lorca Peregrino", por Samuel Diz, com a participação do tenor Jonatan Alvarado.

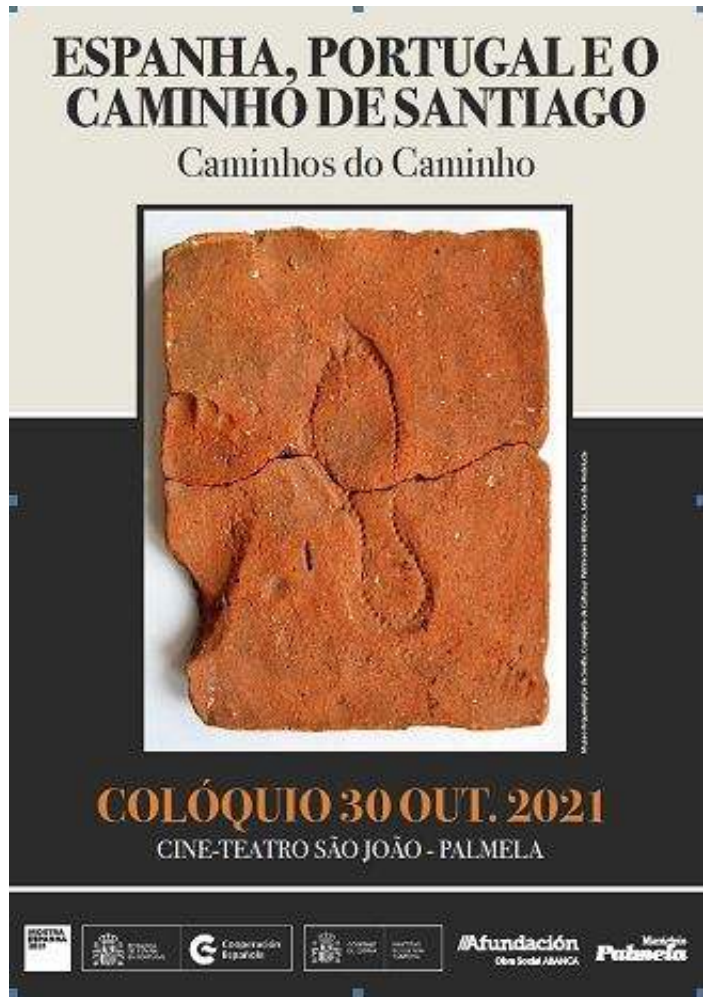

Fig. 4 - Cartaz do Colóquio Espanha, Portugal e o Caminho de Santiago. Caminhos do Caminho. 


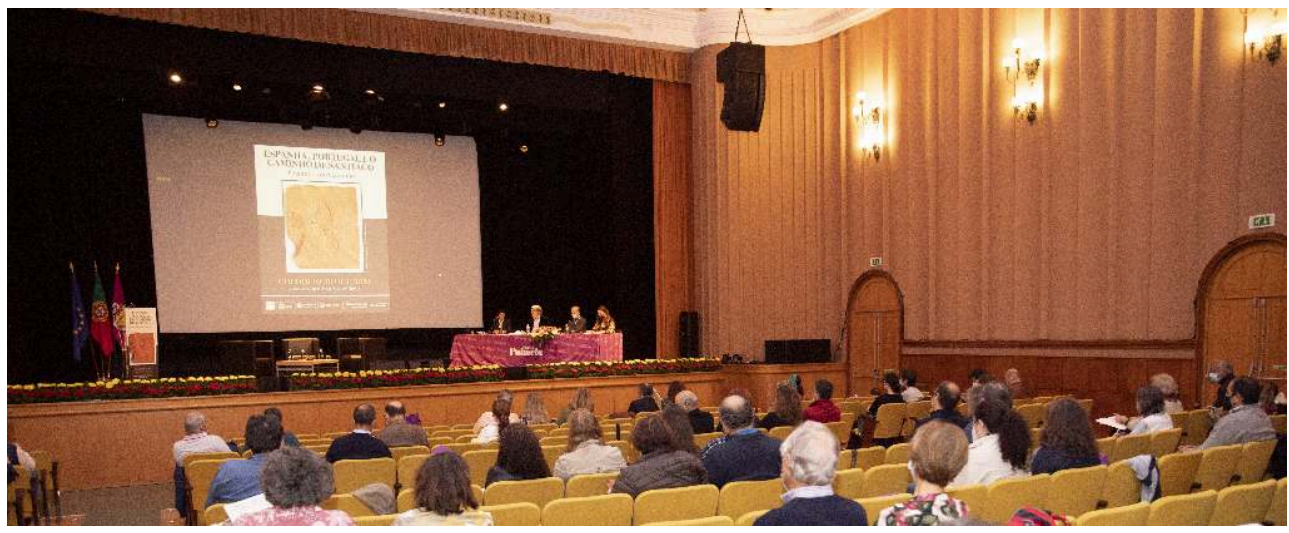

Fig. 5 - Sessão do Colóquio Espanha, Portugal e o Caminho de Santiago. Caminhos do Caminho. Foto Paulo Alexandre - CMP.

18 A edição dos textos apresentados no VIII Encontro sobre Ordens Militares - Ordens Militares, Identidade e Mudança -, realizado em junho de 2019, completa o conjunto de realizações do GEsOS em 2021. 